\title{
RENTABILIDADE DAS EXPORTAÇÕES BRASILEIRAS DE MADEIRA TROPICAL
}

\author{
Humberto Angelo \\ Roberto Tuyoshi Hosokawa'; \\ Ricardo Berger ${ }^{2}$; \\ Luis Hernan Rodríguez Castro ${ }^{3}$
}

\begin{abstract}
RESUMO
Este trabalho estima e analisa as exportações de madeiras serradas tropicais no que diz respeito à rentabilidade. O comportamento dessas exportações foi estimado a partir dos indicadores de taxa real de câmbio e de rentabilidade para melhor explicar o desempenho das exportações das madeiras tropicais brasileiras, para o período de 1972 a 1994. A rentabilidade das exportações foi crescente até meados da década de 80, a partir de então, uma queda acentuada foi verificada.

Palavras-chave: rentabilidade, madeiras tropicais, exportações e mercado internacional
\end{abstract}

\section{PROFITABILITY OF BRAZILIAN TROPICAL SAWNWOOD EXPORTS}

\begin{abstract}
This work analyses the Brazilian tropical sawn wood exports, taking into consideration its performance and profitability. Indexes of real exchange rate and export profitability were estimated for the period 1972-94 in order to better explain the Brazilian sawn wood competitiveness in the international market. It was found that the profitability of the exports increased until the middle of the 80's. Since then, an accentuated decline was verified. Key-words: profitability, tropical sawn wood, exports and international market
\end{abstract}

\section{INTRODUÇÃO}

O Brasil possui quase um terço das florestas tropicais úmidas da Terra, o equivalente a 300 milhões de hectares, correspondendo a um potencial exportável estimado em pelo menos 15 bilhões de metros cúbicos de madeira. Em 2001, a produção brasileira de madeira tropical em tora foi de aproximadamente 26,5 milhões de metros cúbicos (ITTO, 2001).

As exportações brasileiras de madeira serrada tropical alcançaram a cifra de 1,10 milhões de $\mathrm{m}^{3}$ com faturamento de US\$ 306,852 milhões em 2000, o que representa $13,09 \%$ do quantum do comércio mundial de madeiras serradas tropicais (ITTO, 2001).

De acordo com Mather (1997), o mercado mundial da madeira está passando por mudanças profundas que estão restringindo a competitividade dos países produtores de madeira tropical . Essas mudanças emergem de quatro áreas diferentes e têm influenciado o setor madeireiro-florestal nos diversos países de forma gradual. Essas mudanças convergem ou se complementam e as vezes são contraditórias. Essas quatro áreas de transição são: a) transição no manejo florestal: da floresta nativa à floresta manejada e à plantação; b) transição na área florestada: do declínio à expansão da área florestada; c) paradigmas florestais: da floresta pré-industrial à floresta industrial e pós-industrial; e d) integração global: um sistema global de recursos florestais e uma transição industrial do Norte ao Sul.

Desde os anos oitenta, a indústria madeireira está passando por um processo de concentração acompanhado pela criação de uma rede internacional de localidades de

\footnotetext{
${ }^{1}$ Prof. UnB, Caixa Postal 04357, 70910-900 - Brasília - DF, e-mail: humb@terra.com.br

${ }^{2}$ Prof. UFPR, Caixa Postal 4088, 82501- 970 - Curitiba-PR.

${ }^{3}$ Prof. UnB, Caixa Postal 04357, 70910-900 - Brasília - DF
} 
produção e processamento de madeira dentro das grandes companhias transnacionais (Dudley; Jeanrenaud; Sullivan, 1996 e Mather, 1997). As inovações tecnológicas descritas anteriormente não só possibilitaram esse processo mas libertaram a indústria madeireira da dependência de recursos florestais nativos, como também incentivaram à internacionalização através da integração vertical entre a produção e o processamento, o qual se transformou em um fator central de competitividade. Além disso, a integração vertical, quer dizer o estabelecimento de plantações e os investimentos em novos equipamentos de produção requerem grandes somas de capital inacessíveis para empresas de pequeno médio porte (Scholz, 1998).

Com relação às exportações brasileiras de madeiras tropicais, alguns trabalhos atribuem a expansão do Brasil no comércio internacional de madeiras tropicais à exaustão das florestas do Sudeste Asiático e ao dinamismo e ao crescimento do comércio mundial. É pouco provável que o crescimento das importações mundiais de madeiras tropicais ( $1 \%$ ao ano) seja o responsável maior pela expansão de 7\% ao ano, no período 197283 , e de $3 \%$ ao ano no período $1984-94$, das exportações brasileiras de madeiras tropicais (Angelo, 1998).

Considerando o importante papel do Brasil no mercado de madeiras tropicais e as transformações vividas no setor industrial madeireiro, às quais se somam as questões ambientais, justifica-se conhecer $o$ comportamento das exportações brasileiras e seus efeitos à Floresta Amazônica.

Assim sendo, este trabalho objetiva estimar e analisar a rentabilidade das exportações brasileiras de madeiras tropicais, no período de 1972 a 1994, tendo a Região Amazônica como base produtora.

\section{METODOLOGIA}

\section{Base Teórica}

A competitividade da madeira brasileira no mercado internacional depende de uma série de fatores: da tecnologia disponível e da eficiência com que é utilizada, dos preços domésticos dos insumos de produção, da taxa de câmbio e das taxas de paridade entre os parceiros comerciais do Brasil, da distância dos países competidores aos mercados de exportação brasileiros, dos custos portuários e de transporte, da estrutura de incentivos e subsídios à exportação no Brasil e nos países competidores, das barreiras tarifárias e nãotarifárias nos países importadores, da qualidade e da imagem do produto, do tipo de financiamento à produção e à comercialização, dos gostos e das preferências e de outros fatores (Pinheiro et al., 1992). A multiplicidade e a diversidade de variáveis que influenciam a competitividade fazem com que este conceito, ainda que aparentemente simples, permita as mais variadas definições associadas a diferentes indicadores.

O conceito de competitividade está associado ao indicador ou ao conjunto de indicadores escolhidos para determiná-lo. Neste sentido, Sharples (1990) comenta que "Competitividade não tem uma definição na teoria econômica neoclássica; ela é um conceito político".

Pinheiro et al. (1992) enumeram três linhas conceituais diferentes para avaliar o grau de competitividade de uma economia ou setor: os conceitos desempenho, macro e eficiência.

O conceito desempenho associa competitividade de um país ao seu desempenho no mercado internacional. Tratase de um conceito amplo, mas que procura identificar os fatores determinantes $\mathrm{da}$ competitividade.

$\mathrm{O}$ segundo grupo de indicadores baseia-se no conceito macro, no qual se avalia a competitividade a partir de variáveis que dependem basicamente de decisões de política econômica, tais como taxa de câmbio, subsídios e incentivos às exportações e política salarial. Esse enfoque atribui grande importância à desvalorização do câmbio como forma de ganhar competitividade. Os indicadores mais tradicionais neste grupo são a taxa de câmbio efetiva real e a relação câmbio salário.

O conceito eficiência associa a competitividade de uma economia às suas características estruturais, ou seja, à capacidade de o país produzir determinados bens, com níveis de eficiência e qualidade iguais ou superiores aos seus competidores. Nesse grupo, alguns indicadores são os gastos em pesquisa e desenvolvimento tecnológico como proporção do PIB, a compra de patentes 
ao exterior ajustada pelo grau de abertura da economia.

\section{Rentabilidade das Exportações}

Como já mencionado, há diversos fatores que afetam a competitividade das exportações de um país. São eles: a taxa doméstica de inflação, a taxa de inflação no resto do mundo, as variações da produtividade e as mudanças na taxa de câmbio. É possível desenvolver várias medidas de competitividade, cada qual com suas vantagens e desvantagens.

Sob a ótica da demanda, a variável preço relativo relevante para avaliar a competitividade das exportações seria a razão entre o preço das exportações e uma média ponderada dos preços de seus principais competidores.

Daí, propôs-se um indicador no conceito macro de competitividade - o índice da taxa de câmbio efetiva real $(\theta)$ — para a indústria de madeiras tropicais, que mede a evolução dos níveis de custos na indústria no resto do mundo, em comparação com a evolução dos custos da indústria no Brasil. Este índice é função da taxa de inflação no Brasil, no resto do mundo, da evolução do câmbio dos demais países em relação ao dólar e da taxa de câmbio brasileira. Portanto, a competitividade do Brasil melhora e cresce o potencial de suas exportações, quando a elevação dos preços no resto do mundo é superior à verificada no Brasil, ambos os preços denominados em uma mesma moeda.

O índice da taxa de câmbio efetiva real

$(\theta)$ pode ser calculado, como se segue:

$$
\theta=\mathrm{E} . \mathrm{PW} / \mathrm{PD}
$$

em que:

$\mathrm{E}=$ taxa de câmbio nominal;

$\mathrm{PW}=$ valor unitário mundial das exportações de madeira serrada, como indicador dos índices de preços dos produtos madeireiros em dólares dos principais parceiros comerciais brasileiros;

PD = índice de preço por atacado no Brasil.

Já sob a ótica da oferta, as medidas de competitividade mais relevantes para analisar o desempenho comercial brasileiro deverão ser as de custos relativos e de rentabilidade das exportações confrontadas com o mercado doméstico. Uma medida da rentabilidade das exportações (REXP) foi construída, dependendo diretamente do preço em dólares das exportações brasileiras, da taxa de câmbio, do nível de subsídios e da evolução dos preços domésticos.

$$
\text { REXP }=\text { PX.E.S } / \text { PD }
$$

em que:

$\mathrm{PX}=$ preço $\mathrm{FOB}$ em dólares das exportações de madeira serrada tropical brasileira;

$\mathrm{S}=$ subsídios às exportações; $\mathrm{e}$

$\mathrm{PD}=$ índice de preço por atacado no Brasil.

Os dados utilizados e suas respectivas fontes encontram-se nas notas das tabelas e figuras apresentas na próxima seção do trabalho.

\section{RESULTADOS E DISCUSSÃO}

\section{Taxa de Câmbio Efetiva Real}

A fig. 1 apresenta o índice da taxa de câmbio efetiva real para a indústria madeireira de serrados, no período 1972-94. Este índice, que se aproxima do índice de paridade do poder de compra, indica que as exportações brasileiras de serrados tiveram ganhos de competitividade, principalmente no período 1976-88.

Esse índice reflete basicamente as variações dos índices de preços, no Brasil e resto do mundo, das cotações das moedas dos principais parceiros comerciais brasileiros em relação ao dólar e da taxa de câmbio brasileira.

Ainda na fig. 1 são ilustradas as variações da taxa de câmbio efetiva real pelas variações na relação entre o índice de preço em dólar no Brasil. Assim sendo, torna-se possível explicar as variações da taxa de câmbio real por meio das variações na relação entre os índice de preço por atacado nos Estados Unidos. Os ganhos de competitividade observados a partir de 1989 são basicamente devidos à depreciação das moedas dos parceiros brasileiros com relação ao dólar. Analisando a fig. 1, pode-se notar um ganho de competitividade ao longo da série, com uma queda nos anos 89-90 e retomada a partir de 1991. 
Figura 1: Índice da taxa efetiva real de câmbio para a indústria de madeira serrada tropical, no período de 1972-94, 1972=100

Figure 1 - index of the rate effective real exchange for the tropical sawn wood industry, for the period 1972$94,1972=100$

Índice da taxa de câmbio real para madeira serrada Tropical (E.PW/PD)

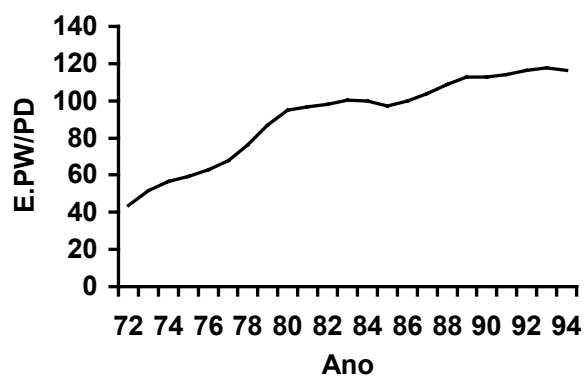

Índice do valor unitário deflacionado pelo índice de preço nos EUA (PW/PUSA)

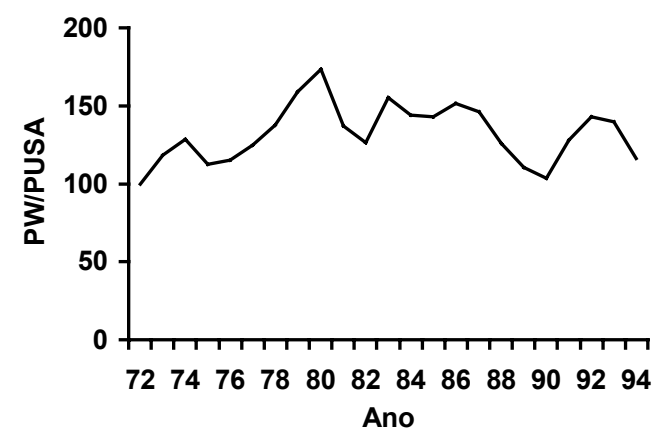

Índice da taxa de câmbio efetiva real em relação ao índice de preço em dólar no Brasil (PUSA/PD.E)

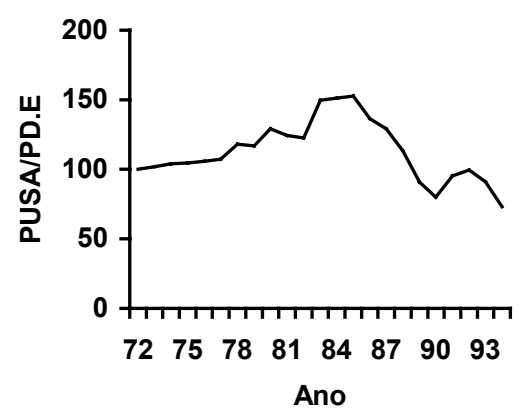

Índice de preço nos Estados Unidos (PUSA)

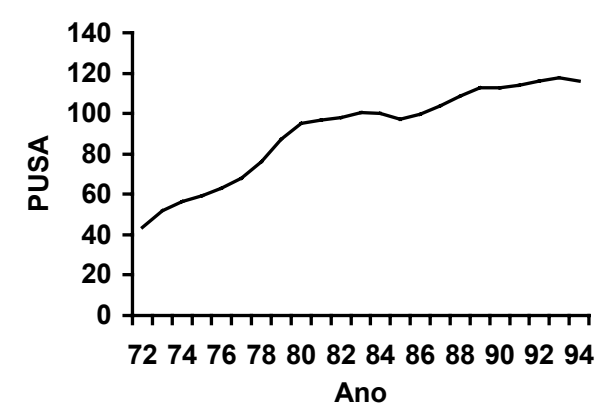

Fonte: Taxa de câmbio nominal (E) BANCO CENTRAL

PW = valor unitário das exportações de folhosas tropical - FAO (1985 e 1996);

$\mathrm{PD}=$ índice de preço por atacado no Brasil -FGV/Conjuntura Econômica, vários anos;

PUSA = índice de preço por atacado nos Estados Unidos - Internacional Monetary Fund, várias edições;

E.PW/PD =Taxa de câmbio real para madeira serrada tropical brasileira;

PW/PUSA = valor unitário mundial das exportações de madeira serrada tropical, deflacionado pelo índice de preço nos Estados Unidos;

PUSA/PD.E = Taxa de câmbio efetiva real em relação ao índice de preço em dólar no Brasil. 
Nos anos de 82-85, os ganhos de competitividade podem ser atribuídos à apreciação das moedas dos parceiros brasileiros em relação ao dólar, e nos anos de 89-94, os ganhos de competitividade podem ser atribuídos ao fato de o índice de preço por atacado em dólar da indústria nacional ter ficado abaixo do observado nos Estados Unidos. Outro fato relevante que explica os ganhos de competitividade das exportações brasileiras de madeiras tropicais é o índice de preço por atacado em dólares ter crescido à taxas inferiores às observadas nos Estados Unidos. Em 1990, verifica-se uma queda acentuada na competitividade da taxa de câmbio efetiva real, embora o Índice de Preço por Atacado (IPA) em dólares tenha sido o menor.

Em resumo, as exportações de madeiras tropicais brasileiras têm sido competitivas devido à apreciação das moedas dos concorrentes brasileiros em relação ao dólar americano, bem como ao índice de preço por atacado em dólares no Brasil ter crescido às taxas inferiores às observadas nos Estados Unidos.

\section{Rentabilidade das Exportações}

Ganhos de competitividade expressivos são observados entre 1972-83 (fig. 2), quando a rentabilidade das exportações com relação às vendas domésticas chegou a $133 \%$ em 1979 e $122 \%$ em 1983. A partir de 1984, observa-se queda deste índice. É possível explicar o índice de rentabilidade pelos subsídios às exportações, pelo índice de preço das exportações em moeda nacional e pelo índice de preço doméstico.
Conforme a fig. 2, os subsídios às exportações e o índice de preço das mesmas afetam de forma diferente a rentabilidade dos exportadores. Entre 1972-83, o aumento da rentabilidade das exportações vis-à-vis as vendas para o mercado doméstico é explicada pela evolução dos preços das exportações com relação ao preço doméstico. A partir de 1987, observa-se uma tendência de queda da relação entre o índice de preço doméstico e os subsídios. Pelo fato de que os subsídios permaneceram praticamente constantes, a partir de 1980, o aumento da rentabilidade das exportações, no período, deve-se basicamente à elevação da relação entre o índice de venda externa em moeda nacional e o índice de preço doméstico.

Os resultados obtidos para a evolução do indicador de rentabilidade são consistentes com o desempenho do setor exportador de madeiras tropicais brasileiras, que no período 1972-83 cresceu 8,02\% ao ano; já no período subseqüente, 1984-93, as exportações cresceram a taxas bem mais modestas, de $3,16 \%$ ao ano. No período como um todo, 1972-94, o crescimento do quantum exportável foi de $3,79 \%$ ao ano (Angelo, 1998).

Os ganhos de competitividade, no período 1988-94, deram-se em virtude da impulsão das exportações a partir de 1993; no entanto, a rentabilidade e a remuneração declinaram no final da série estudada 1972-94. $\mathrm{O}$ contingenciamento das exportações de espécie valiosa como o mogno, pode ter contribuído com este cenário, juntamente com a queda dos preços das madeiras brasileiras no mercado internacional. 
Figura 2: Índice de rentabilidade das exportações das madeiras tropicais brasileiras vis-à-vis as vendas para o mercado doméstico, no período 1972-94, 1972=100

Figure 2: Index of profitability of the brazilian tropical sawnwood exports related to domestic sales, for the period 1972-94, 1972=100

Evolução da remuneração das exportações ([PX.E/PD].S) Índice de rentabilidade das exportações vis-à-vis as vendas para o mercado doméstico (PX.E/PD)

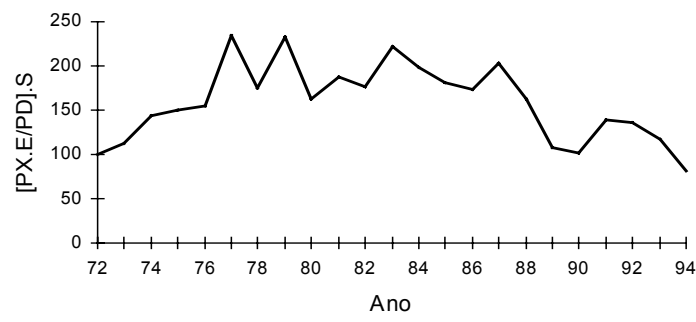

Evolução dos subsídios às exportações (S)

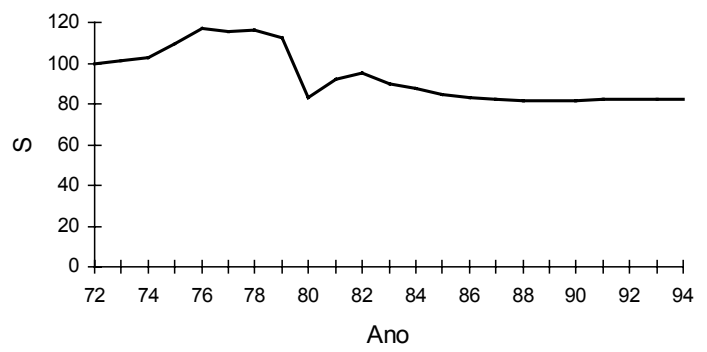

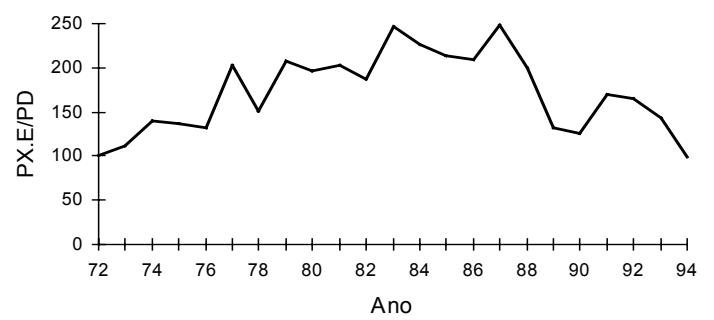

Preço FOB das madeiras tropicais brasileiras em relação ao preço mundial FOB das mesmas (PX/PW)

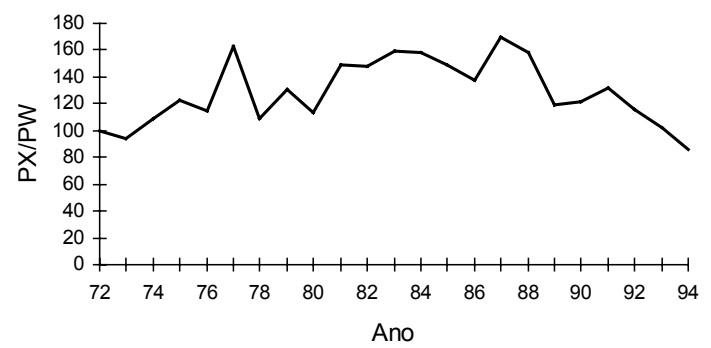

Índice da taxa de câmbio real para madeiras tropicais (E.PW/PD)

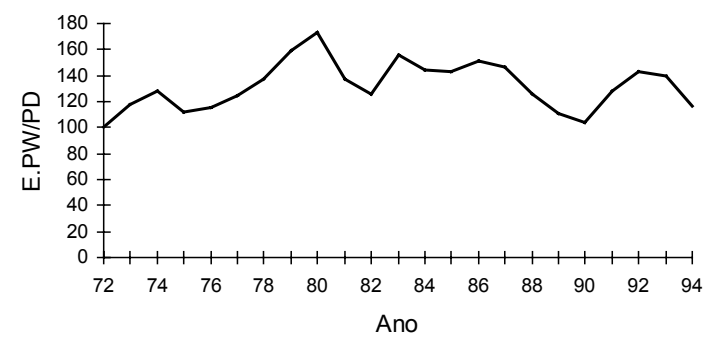

Fonte: Taxa de câmbio nominal (E) BANCO CENTRAL; PW = valor unitário das exportações de madeira tropical - FAO (1985 e 1996); PX = preço FOB em dólares das exportações de madeira serrada tropical brasileira - FAO (1985 e 1996); PD = índice de preço por atacado no Brasil FGV/Conjuntura Econômica, vários anos; $\mathrm{S}$ = índice de subsídio às exportações - Musalem (1981) para o período 1972-79 e Pinheiro, Borges e Zagury (1993) para o período 1980-92 e para 1993 e 1994 o valor foi estimado pelos autores. [PX.E / PD].S = remuneração das exportações; PX.E / PD = rentabilidade das exportações vis-à-vis as vendas para o mercado doméstico; $\mathrm{PX} / \mathrm{PW}=$ preço $\mathrm{FOB}$ das madeiras serrada tropical brasileira em relação ao preço internacional FOB das madeiras serradas tropicais. 


\section{CONCLUSÕES}

- A rentabilidade das exportações foi crescente até meados da década de 80, beneficiada principalmente pelos subsídios e pela taxa real de câmbio; a partir de então, uma queda acentuada foi verificada. A necessidade de políticas para aumentar a rentabilidade das exportações de madeiras serradas tropicais fica evidenciada. Entre estas, estão uma política comercial mais agressiva no sentido de abrir e expandir novos mercados. Consolidar marcas, introduzir novas espécies, agregar valores aos produtos, modernizar o parque industrial madeireiro, diferenciar os produtos no sentido de promover um consumo mais sofisticado da madeira tropical, certificar os produtos florestais sob sistemas de manejo, são políticas a serem implementadas de imediato.

- A consideração geral deste estudo é de que a rentabilidade da atividade madeireira encontra-se em processo de declínio. Este fato implica na sustentabilidade da floresta tropical brasileira, uma vez que os exportadores para compensar as perdas de rentabilidade tende a uma procura seletiva de espécies mais valiosas a custos menores. Muitas das vezes esta oferta de matéria prima encontra-se nas florestas não manejada, daí o comprometimento com a sustentabilidade da floresta tropical.

- Finalmente, é interessante levantar sugestões para novas pesquisas. Recomendase, nas futuras investigações, questionar a atual intensificação de capital na indústria madeireira amazônica e estudar a expansão das exportações de madeiras tropicais, e seus respectivos impactos na floresta tropical.

\section{REFERÊNCIAS}

ANGELO, H. As exportações brasileiras de madeiras tropicais. Curitiba: UFP. 1998. Tese (Doutorado em Engenharia Florestal) Universidade Federal do Paraná. 1998.

DUDLEY, N.; JEANRENAUD J. P.; SUlliVAN, F. (1996). Bad harvest? The timber trade and the degradation of the world's forests. Londres: Earthscan
FAO. Yearbook of forest products 1983. Rome, 1985. 408 p. (FAO Forestry Series, 18. FAO Statistical Series. 60)

FAO. Yearbook of forest products 1994. Rome: 1996. 408 p. (FAO Forestry Series, 29. FAO Statistical Series. 128)

FGV. Conjuntura Econômica. Rio de Janeiro: várias edições.

ITTO. Annual review and assessment of the world timber situation 2001. International Tropical Timber Organization. Yokohama, Japan: 2001. 118 p.

MATHER, A. (1997). South-North Challenges in Global Forestry. Helsinki: UNU/WIDER Working Paper No. 145

MUSALEM, A. R. Política de subsídios as exportações de manufaturados no Brasil. Revista Brasileira de Economia. v. 35, n. 1, p. 17-41, 1981.

PINHEIRO, A. C.; BORGES, C. P.; ZAGURY, S. Incentivos fiscais e creditícios à exportação: resultados setoriais 1980/91. Rio de Janeiro: IPEA, 1993. 60 p. (texto para discussão, 2 ).

PINHEIRO, A. C.; MOREIRA, A. B.; HORTA, M. H. T. T. Indicadores de competitividade das exportações: Resultados setoriais para o período $1980 / 88$. Rio de Janeiro: IPEA, 1992. 60 p. (texto para discussão, 257).

SCHOLZ, I. Comércio, meio ambiente e competitividade: $O$ caso da indústria madeireira do Pará. Brasília: Programa de Bolsas Instituto Rio Branco / BID, 1998. 69 p.

SHARPLES, J. A. Cost of production and productivity in analysing trade and competitiveness. American Journal of Agricultural Economics, p. 1.278-1.282, Dec. 1990. 